\title{
1 The role of floral traits in community assembly process at high elevations in Lesser
}

\section{Himalaya}

3

4 Mustaqeem Ahmad ${ }^{1,2,3}$, Sergey Rosbakh ${ }^{4}$, Solveig Franziska Bucher ${ }^{5,6}$, Padma Sharma ${ }^{1}$,

5 Sonia Rathee ${ }^{2}$, Sanjay Kr. Uniyal ${ }^{3,}$ Daizy R. Batish ${ }^{2} \&$ Harminder P. Singh ${ }^{1}$

6

$7 \quad{ }^{1}$ Department of Environment Studies, Panjab University, Chandigarh, India

$8 \quad 2$ Department of Botany, Panjab University, Chandigarh, India

$9{ }^{3}$ Department of Environmental Technology, CSIR-IHBT, Palampur, India

$10{ }^{4}$ Ecology and Conservation Biology, University of Regensburg, Germany

$11{ }^{5}$ Institute of Ecology and Evolution, Plant Biodiversity Group, Friedrich Schiller University

12 Jena, Jena, Germany

$13{ }^{6}$ German Centre for Integrative Biodiversity Research (iDiv) Halle-Jena-Leipzig, Germany 


\section{Abstract}

15 1. Ecological theory postulates that plant trait research should consider multiple traits related

16 to different organs and/or ontogenetic stages as such traits represent different ecological

17 niche axes. Particularly, floral traits have been suggested to play an important role in

18 assembling plant communities along environmental gradients as they determine the reproductive success, one of the key functions in plants. Yet, the predictive power of floral

20 traits in community assembly research remains largely unverified empirically.

21 2. We analyzed the predictive power of six floral traits of 139 herbaceous species for

22 inferring community assembly process in twenty-one sites located along an elevation

23 gradient in Lesser Himalaya ranging from 2,000 to 4,000 meters above sea level. The floral

24 trait variability along the gradient was analyzed using community-weighted trait mean

25 (CWM) values and functional diversities (FD) calculated for each of the study

26 communities.

27 3. The CWM values for onset of flowering and flower display area increased significantly

28 with increasing elevation, whereas specific flower area showed an opposite pattern. In

29 combination with convergence in onset of flowering and specific area (i.e., lower FD

30 values in high elevation sites), these patterns suggest that abiotic filtering and plant-

31 pollinator interactions affected the floral trait composition of the communities studied.

32 Increasing low-temperature stress towards high-elevation sites selected for late-flowering

33 species that produce resource-intensive flowers with larger display areas.

34 4. Low pollinator abundancy and activity in high elevation, could also explain why these

35 traits were selected in the study communities. Delayed flowering with increasing

36 elevations might facilitate the phenological overlap of plants and their pollinators, as

37 pollinator activity at higher elevation peaks in the second half of the vegetation period. The

38 dominance of species with low specific flower area and larger display area in high 
elevation communities were attributed to the increased flower longevity and attraction of pollinators, respectively, to maximize pollination success under pollinator scarcity.

41 5. Synthesis. Our study provides empirical support of the recent argument that floral traits contribute considerably to the assembly of plant communities along environmental gradients. Thus, such traits should be included into community assembly research agenda

Keywords: biotic interaction, elevation, filter, flower, gradient, pollinator, temperature

Introduction

Understanding the processes shaping the structure and composition of biological communities

along environmental gradients, i.e., the community assembly mechanisms (Keddy, 1992), is

one of the fundamental aims in ecological research. Disentangling abiotic and biotic factors selecting for or against species from the regional to local species pools allows us not only to understand the current community compositions but can also help to answer the question how these communities will respond to future environmental changes (Götzenberger et al., 2012). lenses of trait-based approaches (McGill et al., 2006). These methods are built on the

57 paradigm that functional traits, that is the physiological, morphological or phenological

58 characteristics of a plant individual which directly affect its growth, reproduction, and

59 survival (Violle et al., 2007), determine species' responses to abiotic environment and biotic

60 interactions (Pillar et al., 2021). Therefore, trait variability within a community reflects the

61 outcomes of abiotic filtering and biotic interactions which are two key assembly rules (Bello

62 et al., 2013; Spasojevic \& Suding, 2012) across different scales (Kraft et al., 2008, Weiher et

63 al., 2011). 
64 There is a common agreement that, to maximize our understanding of trait-based

65 community assembly, traits related to different organs should be considered as they relate to

66 different ecological niche axes (Grime et al., 1997; Laughlin, 2014). However, the published

67 studies are biased strongly towards traits connected to vegetative growth, survival and

68 resource acquisition (i.e., vegetative traits) with traits related to sexual reproduction being

69 largely ignored (E-Vojtkó et al., 2020; Jiménez $\square$ Alfaro et al., 2016; Rosbakh et al., 2018),

70 therefore, including these traits into the current research agenda is important to predict

71 complex environmental effects on trait composition within communities (E-Vojtko et al.,

72 2020; Poschlod et al., 2013; Rosbakh et al., 2018).

73 In this context, floral traits, physiological, morphological and phenological characteristics

74 of flowers and inflorescences and the way they are pollinated (Klotz et al., 2002), are of a

75 particular interest. Several floral traits, such as the number of flowers, flower display area,

76 scent, and petal colour, determine the success of reproduction, one of the main functions in

77 plants (Barrett, 2010; Soltis \& Soltis, 2014). Thus, to maximize plant reproductive fitness,

78 these traits display strong intra- and interspecific variability along environmental gradients

79 reflecting adaptations in plants to specific abiotic conditions and/or pollinator availability (E-

80 Vojtkó et al., 2020). For example, soil moisture availability limits plant investment in flowers

81 with smaller floral area in dry habitats (Lambrecht \& Dawson, 2007). Further, Burkle and

82 Irwin (2010) reported that low soil nitrogen content has direct effects on survival and adult

83 fecundity, and results in increased length of flowering stalks. These findings suggest that, at

84 the community level, abiotic filtering could select floral traits and thus leads to shifts in

85 community functional trait composition. Another potential driver of community assembly

86 process in flowering plants is plant-plant and plant-pollinator interactions, for which previous

87 research has indicated that some floral traits (e.g., flower morphology, colour, and scent) can

88 be involved in competition and facilitation via pollinators (Sargent \& Ackerly, 2008).

89 Pollinators, particularly, bees can differentiate between flower temperatures which influences 
90 their behaviour as they prefer warm flowers (with larger display area) and warm nectar over

91 unheated ones (Dyer et al., 2006). Norgate et al. (2010) reported that this behaviour becomes

92 more pronounced with decreasing temperatures. Learning behaviour of pollinators may

93 indirectly enhance successful pollination via their preference for some colours through their

94 ability to associate flower temperature with specific colours (van der Kooi et al., 2019).

95 Additionally, this learning behaviour can also affect flowering communities through

96 frequency of their visitation as inexperienced pollinators may be attracted to larger display

97 areas whereas experienced pollinators prefer greater floral rewards (Makino \& Sakai, 2007).

98 Finally, some phenological traits, such as onset and duration of flowering, can be affected

99 by both, abiotic filtering, and biotic interactions (Bucher \& Römermann, 2020; Ulrich et al.,

100 2020). Temperature has been reported to influence flowering phenology as higher

101 temperatures lead to an advance in first flowering day (Menzel et al., 2006). Similarly,

102 temperature also displays strong association with flowering duration, with warmer

103 temperature leading to extended flowering period (Bucher \& Römermann, 2020; Campbell \&

104 Halama, 1993). On the other hand, biotic interactions via pollinators also impact flowering

105 duration as animal-pollinated flowers have a higher flowering duration as compared with

106 wind-pollinated plants (Bucher \& Römermann, 2020; Rabinowitz et al., 1981).

107 The aim of this study was to examine the role of six selected floral traits - onset of

108 flowering, flowering duration, flower number, flower investment, flower display area and

109 specific flower area - for inferring community assembly process along an elevational gradient

110 in the Lesser Himalaya. Using in-situ measured trait data for 139 herbaceous species

111 occurring in 21 sites ranging from 2,000 to 4,000 $\mathrm{m}$ above sea level (a.s.1.), we analysed

112 variation in community-weighted trait mean (CWM) values and functional diversities (FD),

113 two key metrics of community functional structure (Ricotta \& Moretti, 2011), to infer the

114 community assembly processes. Specifically, given the increasing low-temperature stress

115 towards higher elevations and high frost-sensitivity of flowers (Wagner et al., 2011), we 
116 anticipated a significant shift in plant strategies towards stress-avoidance by delaying the

117 onset of flowering and consequently shorter flowering duration in high elevation communities

118 (Ahmad et al., 2021; Bucher \& Römermann, 2020; Table 1). In addition to that, the short

119 growth period with frequent and severe frosts coupled with generally limited soil resources

120 was expected to select for species which allocate their resources to vegetative growth rather

121 than to sexual reproduction (Laiolo \& Obeso, 2017; Rosbakh \& Poschlod, 2021). In terms of

122 floral traits, we hypothesized that communities at higher elevations are assembled by species

123 which produce fewer flowers with smaller specific flower area and invest less into flower

124 biomass and consequently have smaller floral display areas. In other words, the strong abiotic

125 filtering at high elevations should lead to significant decrease in the CWMs and stronger trait

126 convergence (low FD values) in all six traits (except for increasing CWMs for onset of

127 flowering) with increasing elevation.

128 Alternatively, we hypothesized that elevation-specific plant-pollinator relationships also

129 affect functional composition of the communities. Considering that higher elevational sites

130 observe generally sparse vegetation and lower pollinator abundance (Körner, 2021; Trunschke

$131 \&$ Stöcklin, 2017), we expected to observe a pattern of delayed and synchronized flowering

132 that continues for a longer period at high-elevational communities as a strategy to maximize

133 pollinator visits and thus to increase the possibility of successful pollination. In other words,

134 the CWMs for the onset of flowering and flower duration were expected to decrease and

135 increase, respectively, along the elevational gradient. The increasing role of facilitation with

136 increasing elevation (i.e., synchronized flowering will attract pollinators and thereby increase

137 the chances of pollination for all community members; Tachiki et al., 2010) should be

138 reflected in the FD variation. Particularly, comparatively higher competition for pollinators in

139 lower elevations was anticipated to result in trait divergence (higher FD at lower than at

140 higher elevation). With respect to the decreasing pollinator abundance along the elevational

141 gradient, we further hypothesized an increase in flower number, specific flower area, flower 
142 display area and flower investment in high elevation communities, as it could be

143 advantageous to enhance pollinator attraction in fragmented alpine habitats combined with a

144 short flowering season and generally low pollinator abundance (Fabbro \& Körner, 2004; Zhu

145 et al., 2010; Körner, 2021). That is, the CWM and FD values should increase and decrease

146 with elevation, respectively.

148 Table 1. Overview of floral traits studied and their hypothesized role in the community

149 assembly process with increasing elevation.

\begin{tabular}{|c|c|c|}
\hline Traits & Abiotic filtering & Biotic interactions \\
\hline $\begin{array}{l}\text { Onset of } \\
\text { flowering }\end{array}$ & $\begin{array}{l}\text { Decreases as a stress- } \\
\text { avoidance adaptation. Trait } \\
\text { convergence as a result of } \\
\text { strong environmental filtering }\end{array}$ & $\begin{array}{l}\text { Delayed and synchronized onset of flowering to } \\
\text { maximize pollination success. } \\
\text { Highest trait values and trait divergence in lower } \\
\text { sites due to high competition for pollinators }\end{array}$ \\
\hline $\begin{array}{l}\text { Duration of } \\
\text { flowering }\end{array}$ & $\begin{array}{l}\text { Shorter as onset of flowering } \\
\text { is comparatively later }\end{array}$ & $\begin{array}{l}\text { Longer to increase chance to be pollinated. Trait } \\
\text { divergence in lower elevation due to } \\
\text { comparatively high competition for pollinators. } \\
\text { Higher elevation: trait divergence due to } \\
\text { facilitation effects }\end{array}$ \\
\hline Flower number & $\begin{array}{l}\text { Fewer at higher elevations } \\
\text { due to resource limitations } \\
\text { and risky sexual reproduction }\end{array}$ & $\begin{array}{l}\text { More at higher elevations (clustering of flowers) } \\
\text { for increased pollinator attraction and visitation. } \\
\text { Strong trait convergence due to high facilitation } \\
\text { effects }\end{array}$ \\
\hline $\begin{array}{l}\text { Specific flower } \\
\text { area }\end{array}$ & $\begin{array}{l}\text { Smaller at higher elevations } \\
\text { due to low resource } \\
\text { availability }\end{array}$ & $\begin{array}{l}\text { Increases along elevation to ensure successful } \\
\text { pollination and fertilization. Trait divergence in } \\
\text { lower elevation due to competition for pollinators }\end{array}$ \\
\hline
\end{tabular}




\begin{tabular}{|c|c|c|}
\hline $\begin{array}{l}\text { Floral display } \\
\text { area }\end{array}$ & $\begin{array}{l}\text { Smaller at higher elevations } \\
\text { due to fewer resources and } \\
\text { uncertain sexual reproduction }\end{array}$ & $\begin{array}{l}\text { Larger at higher elevation to attract pollinators. } \\
\text { Strong trait convergence at higher elevation due to } \\
\text { high facilitation effects }\end{array}$ \\
\hline $\begin{array}{l}\text { Flower } \\
\text { investment }\end{array}$ & $\begin{array}{l}\text { Decreases with increasing } \\
\text { elevation because of } \\
\text { increasing unfavorability for } \\
\text { sexual reproduction }\end{array}$ & $\begin{array}{l}\text { Higher in higher elevation to attract pollinators } \\
\text { and ensure successful sexual reproduction. Strong } \\
\text { trait convergence due to high facilitation } \\
\text { effects. Trait divergence in lower elevation due to } \\
\text { plant-plant competition for available pollinators }\end{array}$ \\
\hline
\end{tabular}

150

151 Materials and methods

\section{Study system}

153 The study was conducted in the Dhauladhar mountain range, Lesser Himalayas (Himachal

154 Pradesh, NW India; Fig. 1). The region is situated at the junction of western, north-western,

155 and trans-Himalayan ranges and is characterized by high levels of floral and faunal diversity

156 due to the combination of diverse geomorphological, geological, and climatic factors (Ahmad,

157 2021). The study region has a typical alpine relief, with steep mountain peaks reaching up to

158 6,200 $\mathrm{m}$ a.s.1.. The bedrocks of the Dhauladhar ridge are mainly composed of granite and

159 gneiss (Singh \& Singh, 1987). The region has a temperate climate with the growth period

160 lasting from April to September in lowlands with average temperatures of $20^{\circ} \mathrm{C}$

161 (https://www.adb.org/). There is a decrease in mean annual temperatures with a lapse rate of

$1626.5^{\circ} \mathrm{K} \mathrm{km}^{-1}$ of elevation (Kattel et al., 2013). The precipitation pattern in Himachal Pradesh is

163 mainly governed by western disturbances and southwest monsoon (Jaswal et al., 2015). Mean

164 annual precipitation in the region is about 2,900 $\mathrm{mm} \mathrm{a}^{-1}$ (Jaswal et. al., 2014) with a

165 pronounced rainy season from July to September (Singh \& Singh, 1987).

166 The vegetation in the study region between 2,000 and $4,000 \mathrm{~m}$ a.s.l. is formed by mixed

167 forests with dominance of Abies pindrow, Aesculus indica, Cedrus deodara, Pinus 
168 wallichiana, Picea smithiana, Quercus semecarpifolia and Rhododendron arboretum. The

169 tree line starts at around 3,000 m a.s.l.; above the tree line herbaceous species like Aconitum

170 heterophyllum, Iris kemaonensis, Lindelofia macrostyla, Meconopsis aculeata, Polygonum

171 amplexicaule, Potentilla argyrophylla and Rumex nepalensis dominate the grasslands (Ahmad

172 et al., 2021). The nival zone with sparse and scattered vegetation starts at about 4,300 $\mathrm{m}$ a.s.1..

173 The lower sites are easily accessible and thus experience high anthropogenic pressure in form

174 of grazing, tourism, and logging (Ahmad, 2021). In the alpine vegetation belt, land-use is

175 limited to vertical transhumance of comparatively small flocks of sheep and goat.

176 In 2015, we established 21 permanent plots, each of $20 \times 20 \mathrm{~m}$ in size at every $100 \mathrm{~m}$

177 increase in elevation ranging from 2,000 to 4,000 $\mathrm{m}$ a.s.l. and thus covering the sub-temperate

178 to alpine vegetation belt. The plant community structure and composition in each plot was

179 assessed by systematic sampling using the quadrat method (Bellhouse, 2005). Specifically,

180 within each plot we marked 5 sub-plots of $5 \times 5 \mathrm{~m}$ (a total of 105 sub-plots across elevation)

181 and within these sub-plots, $251 \times 1 \mathrm{~m}$ quadrats (a total of 525 sub-plots across elevation) were

182 marked to record presence-absence and abundance of shrubs and herbs in the community,

183 respectively (Appendix 1). The vegetation in the plots was studied in 2018 during the peak

184 growing season (February to November, depending on elevation).

185 Each site was characterized in terms of temperature, soil nutrients and water supply. We

186 used mean soil temperature at $10-15 \mathrm{~cm}$ soil depth measured during the growing season (June

187 to September) as a proxy for the temperature conditions (Scherer Körner, 2011). The soil

188 temperatures were measured at a 30-minute interval by data loggers (Geo Precision

189 Environment Technology, Germany) each installed in the centre of every permanent plot.

190 To characterise the soil conditions, soil samples were collected from the centre of every

$1915 \times 5 \mathrm{~m}$ sub-plot at each permanent plot, i.e., 5 replicates per plot. The soil samples were air

192 dried. Subsequently, we measured the concentration of available nitrogen, phosphorous and

193 potassium (AN, AP, AK, respectively) as well as water saturation (WS; a proxy for soil 
194 moisture content) following the methods provide by Ahmad et al. (2020). Study sites

195 coordinates, temperature logger code, and mean values of abiotic factors are given in

196 Appendix 2 Table S1.

197

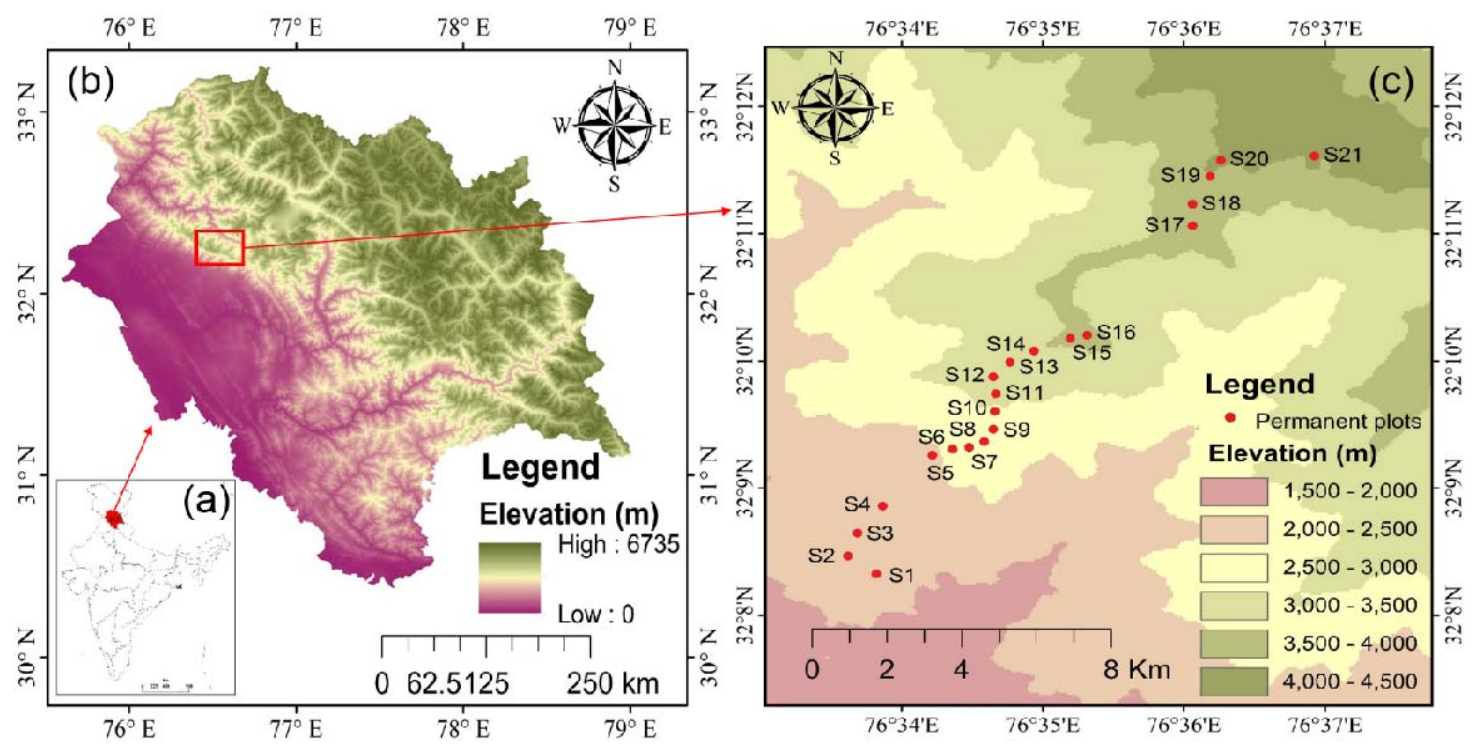

198 Figure 1. The location of the study sites in India (a) and Himachal Pradesh (b), and their spatial orientation along the elevational gradient (c). See Appendix 2 Table S1 for detailed site characteristics.

\section{Trait measurements}

203 Based on the vegetation surveys, we selected the 139 most abundant insect-pollinated species

204 (i.e., species that were present in more than three sites and with an abundance of $>3 \%$ ) from

205 which flower and phenological traits were measured. We conducted regular phenological observations from February to November 2018, we collected data for a total of 10,025 visits

to $1 \times 1 \mathrm{~m}$ quadrats during 401 visits of the 21 permanent plots during the entire study $1 \mathrm{~m}$ ) sub-plots on each $20 \times 20 \mathrm{~m}$ plot. We recorded the flowering stages (bud, open flower, or senescent flower) for every individual of a species in $1 \times 1 \mathrm{~m}$ quadrats. Within these $1 \times 1$ m quadrats, the percent (\%) flowering of each individual (of a species) was estimated. The 
212 flowering $(\%)$ recorded for each individual of a species in $25(1 \times 1 \mathrm{~m})$ quadrats were

213 averaged to represent flowering (\%) of that species' population, for that particular permanent

214 plot $(20 \times 20 \mathrm{~m})$. The day of the year (DOY $1=1^{\text {st }}$ of January), on which the plant species

215 reached 20 and $90 \%$ of floral abundance was considered as the onset, and end of flowering,

216 respectively as described in Valencia et al. (2016) and Ahmad et al. (2021). We also estimated

217 the total flowering duration (TFD) calculated as time span between the end and the onset of

218 flowering (Crimmins et al., 2013). Additionally, two floral traits namely floral display area

$219\left(\mathrm{FDA}, \mathrm{mm}^{2}\right)$ and specific flower area $\left(\mathrm{SFA}, \mathrm{mm}^{2} \mathrm{mg}^{-1}\right)$ were measured following the same

220 protocols as developed for specific leaf area described by Pérez-Harguindeguy et al. (2016).

221 The FDA is the total area of all flowers or inflorescences of one individual at the peak of

222 flowering and is an indicator for the investment of a plant into attracting pollinators (higher

223 values mean higher visibility, pollinator visitation rates and potentially higher fertilization

224 success) (Fabbro \& Körner, 2004; Herrera, 2009; Zhao et al., 2016). SFA is the ratio between

225 one-sided surface area of fresh flower divided by its dry weight and flower/inflorescence

226 biomass, a trait that represents resource investment in reproductive parts (Pérez-Harguindeguy

227 et al., 2016). For the FDA and SFA measurements, 10 to 20 healthy, fully flowering plants

228 were selected for each species at each plot, dug out completely, wrapped in moist towels and

229 transported to the laboratory. Fresh flower area was measured with the help of a digital

230 Vernier calliper (Fabbro \& Körner, 2004). Collected plant species were separated into root,

231 shoot and flowers. These were then dried in oven at $70^{\circ} \mathrm{C}$ for $48 \mathrm{~h}$ followed by weighing

232 using a balance with a precision of $0.1 \mathrm{mg}$. Flower/inflorescences number was recorded

233 manually for each plant species at each plot. Floral investment was calculated as:

$$
\text { Floral investment }=\frac{\text { Flower biomass }}{\text { Total plant biomass }} \times 100
$$




\section{Statistical analysis}

236 The changes in environmental characteristics along the elevational gradient, as well as among

237 all environmental factors, were analysed using the Pearson correlation coefficient. Polynomial

238 regressions were applied to test the effect of rainfall and temperature during the sampling

239 period. A detrended correspondence analysis (DCA) was performed to analyse the

240 relationship between species occurrence and environmental parameters by using the vegan

241 package in R statistical environment (Oksanen et al., 2015). An environmental fitting test with

242999 permutations was performed to analyse correlations of environmental factors with the

\section{DCA axes.}

244 The changes in community functional structure were analysed with the help of community

245 weighted means (CWMs) and functional diversity (FD). A CWM is the average trait value

246 weighted by species' relative abundances in a community and thus describes the adaptation

247 strategy of dominant species to given environmental conditions (de Bello et al., 2021). The

248 FD is a measure of trait dissimilarity compared to random expectation (i.e., trait convergence

249 or divergence) and was calculated using Rao's quadratic entropy (Rao, 1982). The deviation

250 of observed FD from the null expectation, i.e., communities are a random selection of species

251 from the regional pool was tested with the help of null models. We generated null models by

252 permuting the columns (species) of the plot-by-species abundance matrix for each plot

253 (community). Then the standard effect sizes (SES) were calculated to evaluate the deviations

254 of observed functional diversity values from random expectations. SES were calculated as the

255 observed FD value minus the mean of the null-FD divided by the standard deviation of the

256 null-FD. Negative SES indicated that FD was convergent, i.e., lower than expected in the null

257 expectation. Conversely, positive SES indicated that FD is divergent, i.e., higher than the null

258 expectations. Further, we assessed the significance of SES by identifying the proportion of

259 random values that fell below the observed diversity value. The ranks below 0.05 indicated 
260 that FD for a given site was a significant low FD, the ranks above 0.95 indicated significant

261 high FD.

262 The variability of the communities (CWM and FD) along the elevational gradient was

263 estimated with the help of a polynomial regression (i.e., community trait value $\sim$ elevation +

264 elevation $^{2}$ ), to account for possible non-linear trait-elevation relationship. If the quadratic term

265 was not significant, the term was removed.

266 Model assumptions were checked (e.g., homogeneity of variances and normality of

267 residuals) and met in all cases. The flower display area was log-transformed to improve the

268 normality of the residuals. All statistical analyses were performed in R version 4.1.0 (R Core

269 Team 2021).

270

\section{Results}

\section{Variability of environmental conditions along elevational gradient}

273 Soil temperature $(r=-0.98, \mathrm{p}<0.001)$ and available phosphorus in soil $(r=-0.65, \mathrm{p}<0.001)$

274 strongly declined with increasing elevation (Fig. 2). Soil available nitrogen was positively

275 correlated with soil available potassium $(r=0.59, \mathrm{p}<0.001)$ and soil moisture $(r=0.66$,

$276 \mathrm{p}<0.001)$. Temperature and precipitation peaked from June to September in the study area

277 (Appendix 2; Fig. S1). The eigenvalue of the first detrended correspondence axis was 0.59

278 and for the second axis 0.32 (Appendix 2; Fig. S2). Elevation and temperature reflected the

279 main axis of variation in the multivariate space. Elevation showed negative correlation with

280 temperature, woody cover, and available phosphorus, whereas available potassium and

281 available nitrogen showed strong positive correlation with water saturation (Appendix 2; Fig.

282 S2). High gradient length (DCA axis 1=4.22) suggests high $\beta$-diversity. The sites on the

283 extreme left of the gradient (S20, S17) share very few similarities with sites on the extreme

284 right (S5, S6) of DCA axis 1, in terms of environmental factors and vegetation composition

285 (Appendix 2; Fig. S2). 


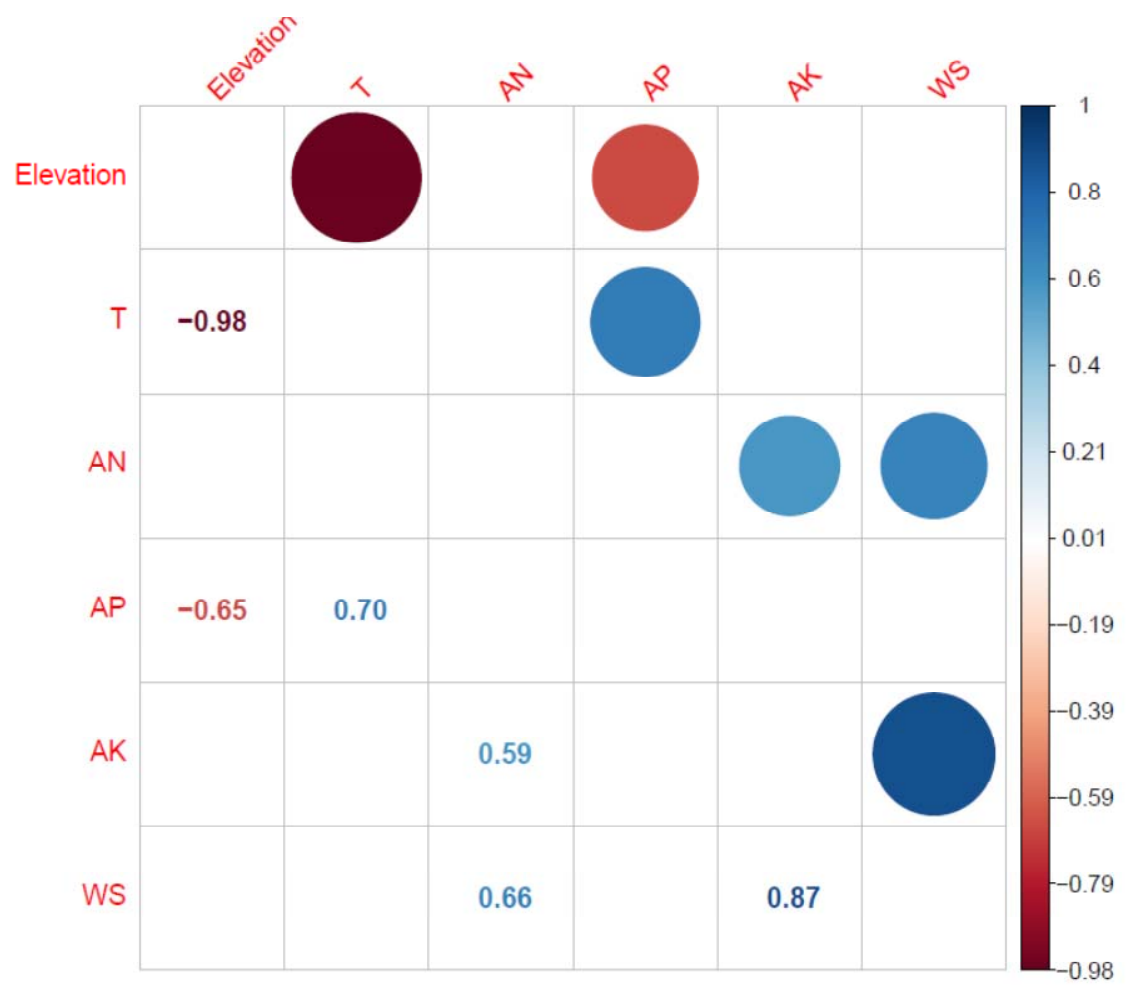

288 Figure 2. Correlation matrix for environmental factors measured in the study sites along the

elevational gradient.

292 CWMs of three out of six traits changed significantly along the elevation gradient (Fig. 3).

293 Onset of flowering increased strongly with increasing elevations from the third week of May

294 (DOY 140) at the lower end of the gradient to the second week of July (DOY 190) in the high

295 elevation areas (Fig. 3A, $\mathrm{R}^{2}=0.84, \mathrm{p}<0.001$ ). Specific flower area displayed an opposite

296 pattern and decreased significantly from $19.6 \mathrm{~mm}^{2} \mathrm{mg}^{-1}$ at $2,100 \mathrm{~m}$ a.s.l. (S2) to $9.2 \mathrm{~mm}^{2} \mathrm{mg}^{-1}$

297 at 3,800 m a.s.1. (S19 site; Fig. 3D, $\mathrm{R}^{2}=0.45$, p<0.001). Floral display area increased with

298 increasing elevation in a non-linear manner (Fig. 3E, $\mathrm{R}^{2}=0.69, \mathrm{p}<0.001$ ) ranging from 8,302

$299 \mathrm{~mm}^{2}$ at $2,500 \mathrm{~m}$ (S6) to the $13,7967 \mathrm{~mm}^{2}$ at 3,100 $\mathrm{m}$ (S10) a.s.1.. In ecological terms, these

300 patterns suggest that dominant species at high elevations tended to flower later, had larger

301 display areas, and were composed of flowers with comparatively more resource-intensive 
302 flowers (i.e., lower SFA values). The duration of flowering, flower number and flower

303 investment did not show any significant variation with elevation (Fig. 3B, C and F,

304 respectively).

305

A

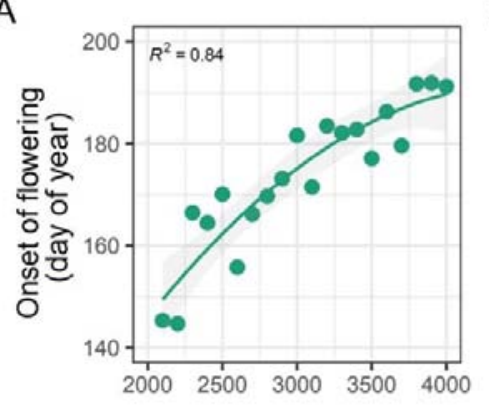

D

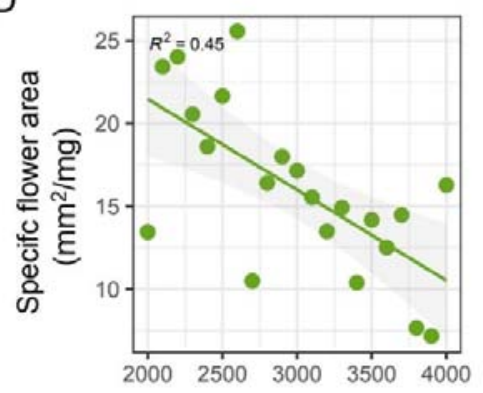

B

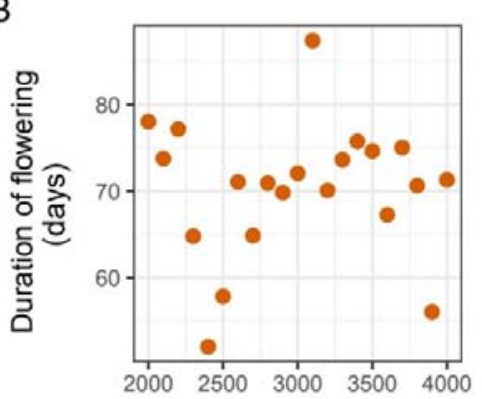

$E$

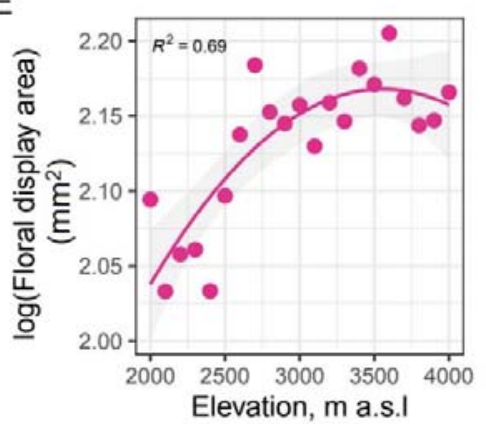

C

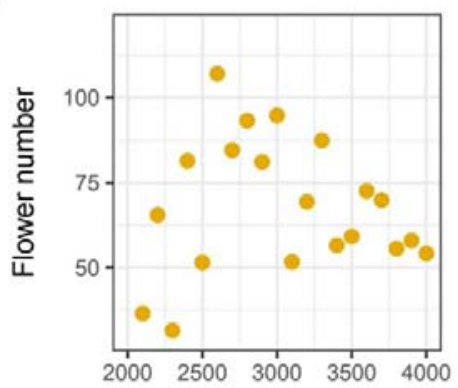

$\mathrm{F}$

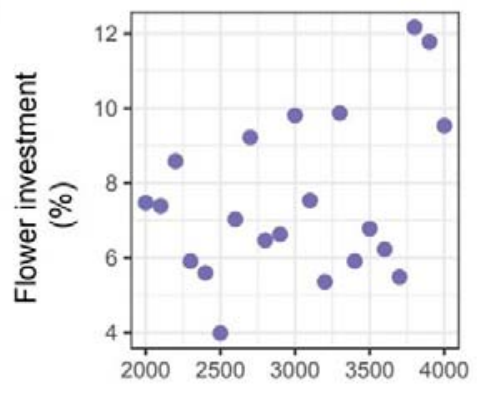

306

307 Figure 3. Variation of community weighted means of six traits along the elevational gradient.

308 Lines indicate significant relationships $(\mathrm{p}<0.05)$, the model error is given as a shading.

Variation of functional diversities along the elevational gradient

311 The FDs of almost all floral traits were non-random across the elevations (Fig. 4). FD of

312 flowering onset decreased strongly from being divergent at lower elevations to comparatively

313 strong trait convergence in high elevation areas (Fig. $\left.4 \mathrm{~A} ; \mathrm{R}^{2}=0.83, \mathrm{p}<0.001\right)$. Additionally,

314 the FD for specific flower area displayed a significant decrease along the gradient towards

315 more convergent trait values at higher elevations, yet the amount of variance explained by this

316 relationship was moderate $\left(\mathrm{R}^{2}=0.32, \mathrm{p}=0.007\right)$. The FD of the remaining traits did not show

317 any significant relationship with the elevation (Fig. 4). 
A

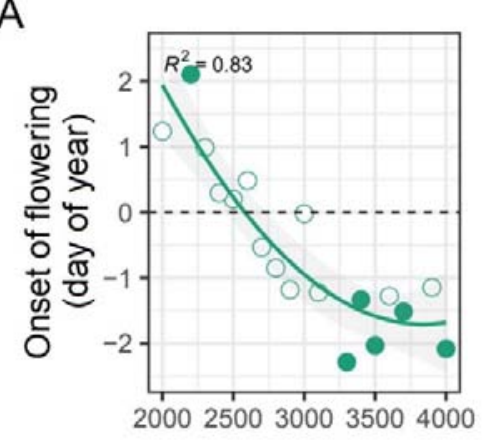

D

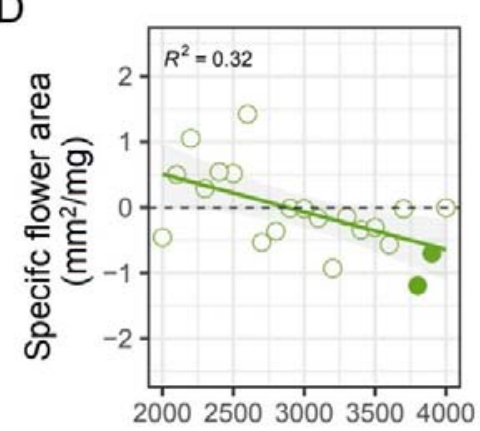

B

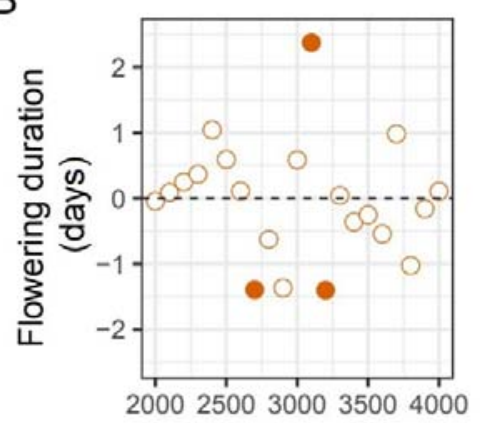

$E$

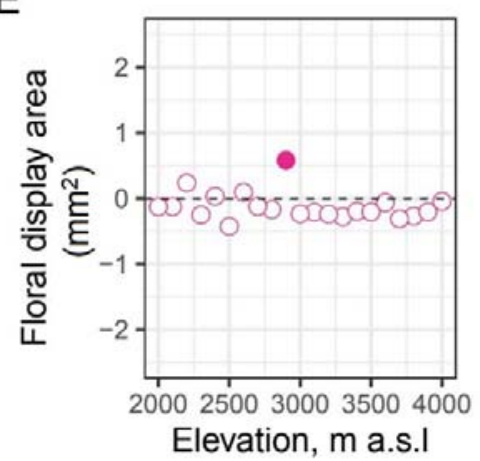

C

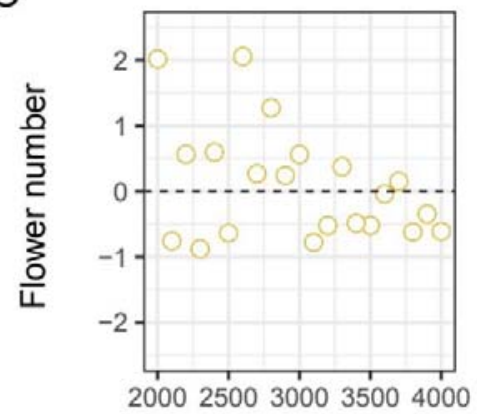

$\mathrm{F}$

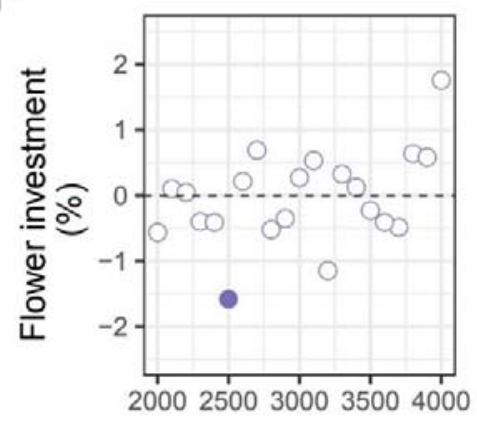

319

Figure 4. Variation of functional trait diversity (FD) of six traits with elevation. Lines

321

322

323

324

325

326

327

328

329

330

331

332

333

indicate significant relationships according to the linear regressions $(\mathrm{p}<0.05)$. Negative and positive standard effect size (SES) indicate a narrower and broader trait range that expected, respectively. Filled circles represent significantly low (rank lower than 0.05) or high (rank above 0.95) FD.

\section{Discussion}

Environmental effects on plant regeneration have long been considered as a key to understand plant population dynamics and species distribution patterns (Grubb, 1977; Woodward \& Woodward, 1987), yet they have been largely neglected in community ecology research (Jiménez $\square$ Alfaro et al., 2016; Poschlod et al., 2013; Saatkamp et al., 2019). Particularly, floral traits, the main determinants of successful sexual reproduction, are rarely considered in research on community assembly (E-Vojtko et al., 2020). In this study, we close this gap and demonstrate that the so far underused phenological and morphological floral traits are 
334 important for plant community structure, especially in high elevational sites. Specificially, we

335 reveal that abiotic filters affect phenological traits (e.g. onset of flowering), whereas plant-

336 pollinator interactions act on flower morphological traits (e.g. floral display area) at the

337 community level.

338 As expected, the temperature decreased along the elevational gradient (Fig. 2) and was the

339 main factor determining the vegetational composition (DCA; Appendix 2 Fig. S2). The low

340 temperature condition selected for late-flowering species (significantly higher CWM values

341 for onset of flowering at higher elevations; Fig. 3). The strong filtering effects of low-

342 temperature could be seen further in the convergent functional diversity of SFA in these sites

343 (Fig. 4A \& D) suggesting exclusion of maladapted early-flowering species. From the

344 ecological point of view, these patterns can be interpreted as a plant phenological strategy to

345 avoid frost injury in frost-susceptible flowers (Wagner et al., 2011), which seem to be a

346 general adaptation of plant reproduction to alpine environments (Körner, 2021). Alternatively,

347 the delayed and synchronised onset of flowering in high elevation areas (strong trait

348 convergence suggest a comparatively low number of available temporal niches for flowering)

349 could be adaptive to facilitate pollination success under conditions with low pollinator

350 abundancy ('magnet' effect; Koski \& Ashman, 2015; Bucher \& Römermann, 2020). Further,

351 delayed flowering with increasing elevation might facilitate plant-pollinator phenological

352 overlap, as pollinator activity at the higher elevation peaks in the second half of the vegetation

353 period, when temperatures are high enough (Rawat, 2012). In contrast, the lower elevational

354 sites seem to harbour a large diversity of plants with different phenological strategies aiming

355 at reducing plant-plant competition for pollinators (Zhao et al., 2016).

356 Interestingly, the significantly later onset of flowering did not affect the duration of

357 flowering in high elevation communities both expressed as CWMs and FDs (Fig. 3B and 4B).

358 These findings contradict previous observations made in other regions that flowering duration

359 decreases with increasing elevations, due to decreasing time window for successful 
360 pollination, fertilization, and consequently seed production (Bucher \& Römermann, 2020;

361 Körner, 2021). The most plausible explanation is that the onset of monsoon season in the

362 study system, which coincides with the peak of flowering, i.e., the middle of the growing

363 period in the Himalayan alpine vegetation belt (Ram et al., 1988), may relax the low-

364 temperature filtering effects on plant phenology and thereby promoting longer duration of

365 flowering. The comparatively long flowering in the resource-limited harsh alpine

366 environments might be achieved by considerably longer life spans of cost-effective flowers

367 (Trunschke \& Stöcklin, 2017; see below). Cumulatively, these findings contradict our

368 hypothesis and suggest that flowering duration plays no important role in the community

369 assembly process in the study system.

370 Analyzing morphological floral traits, we found that CWMs for specific flower area and

371 floral display significantly varied along the elevation gradient with high elevation

372 communities dominated by species with large flower display areas and relatively small SFA

373 values (Fig. 3D). Most likely, these shifts in CWM can be related to the effects of

374 environmental filtering and plant-pollinator interactions on sexual regeneration strategies in

375 alpine environments. As for the former, we assume that low-temperature stress and lower soil

376 fertility (Fig. 2) as well as stronger winds (Körner, 2021) at higher elevational sites select for

377 plants that invest more resources per floral display area unit. In alpine regions, flowers adapt

378 in response to wind induced mechanical perturbations, as heavier flowers have more

379 mechanical tissue that supports the floral unit, making the structures more flexible and

380 aerodynamically stable (Cordero et al., 2007; Zhang et al., 2021). The larger flower display

381 area might be also adaptive in cold alpine climates as it positively correlated with a flowers'

382 passive heat accumulation (Dietrich and Körner, 2014). As for the plant-pollinator

383 interactions, the decreased SFA CWM and FD values can be also attributed to the increased

384 longevity of single flowers at higher elevations to maximize pollination success under

385 conditions of low pollinator abundancy (Fabbro \& Körner 2004; Klatt et al., 2018). Similarly, 
386 a larger display area allows plants from alpine communities to increase pollination probability

387 by attracting more pollinators (Fabbro \& Körner 2004; Kiełtyk, 2021; Zhao et al., 2016).

388 Regardless of the main driver of SFA variability at the community level, this trait seems to

389 play an important role in community assembly process as we observed a significantly higher

390 trait convergence with increasing elevation.

391 Contrastingly to previous studies in alpine environments (Fabbro \& Körner, 2004),

392 resource investment in reproduction ('flower investment') did not change along the

393 elevational gradient. Many studies suggested increase in pollinator visitation rates with

394 increase in flower size and number (Conner \& Rush, 1996). However, a reason for no

395 significant change in flower number with elevation might be that with increasing flower

396 display size the plant does not need to invest more resources to flower number. In addition,

397 Samson and Werk (1986) asserted that for understanding the pattern of resource investment in

398 plants, the species-specific size-dependent effects should be taken into consideration. Obeso

399 (2002) reported that the responses to plant reproductive investment are extremely variable due

400 to previous history, individual variations, timing of reproduction, plant size, plant density,

401 competition, plant architecture, and successional stage.

402 Thus, the interaction of different life-history traits and plant size effects with reproductive

403 investment should be studied to understand the resource allocation strategy of plants across

404 elevation.

405

406 Conclusions

407 The revealed patterns of CMW and FD variations of floral traits have at least three important

408 points for plant ecological research. First, our study clearly demonstrates that in addition to

409 widely used vegetation traits, floral traits can also play a significant role in community

410 assembly process along environmental gradient. Therefore, these finding provide further

411 support to the recent argument that plant research should consider multiple traits representing 
412 different ecological functions including growth, reproduction, and survival (E-Vojtkó et al.

413 2020; Laughlin, 2014; Rosbakh et al., 2021).

414 Second, our findings suggest that the floral traits might be used in applied ecological

415 research to forecast functional community composition shifts in alpine ecosystems. The

416 continuous temperature rise observed in the study region (Sabin et al., 2020) may lead to

417 relaxation of low-temperature stress filtering effects on flowering phenology, specific flower

418 area and floral display area of species adapted to environmental conditions of lower sites,

419 resulting in an altered composition of communities in cold sites (i.e., increase in frequency

420 and abundance of species from lower elevations). The results also revealed a lacuna in our

421 understanding of reproductive investment patterns of species and its interactions with biotic

422 and abiotic constraints along elevation, which might provide additional insights into the

423 factors governing community assembly of flowering plants.

\section{Author contributions}

426 MA, SR, SFB, HPS, DRB and SKU conceive the idea and design the study for this work.

427 MA, SRA, PS and SKU collected the data. MA, SRA, and PS data entry and did the formal

428 analyses. SR and MA analysed the data. MA and SR wrote the first version of the manuscript;

429 all authors contributed to writing of the final version of the manuscript.

431 Acknowledgements

432 Authors are grateful to Ministry of Environment, Forest \& Climate Change, India, for

433 providing financial support under National Mission on Himalayan Studies. MA is thankful to

434 Council of Scientific and Industrial Research (CSIR), India, for providing senior research

435 fellowship. Authors express gratitude to Sanjay Kumar (Director, CSIR-IHBT) who provided

436 the mandatory facilities for the research work at CSIR-IHBT. We also acknowledge Christian

437 Körner and Robert R. Junker for insightful suggestions during the initial stages of project 
438 proposal. We acknowledge Rohit, Om Prakash, Girja Nand, and Ashok Kumar for their

439 assistance in carrying out the fieldwork.

Data accessibility statement

442 Should be manuscript be accepted for publication, the data will be published on Zenodo.

444 References

445 Ahmad, M., Uniyal, S. K., Batish, D. R., Rathee, S., Sharma, P., \& Singh, H. P. (2021).

446 Flower phenological events and duration pattern is influenced by temperature and

447 elevation in Dhauladhar mountain range of Lesser Himalaya. Ecological Indicators,

$448 \quad$ 129, 107902. https://doi.org/10.1016/j.ecolind.2021.107902

449 Ahmad, M., Uniyal, S. K., Batish, D. R., Singh, H. P., Jaryan, V., Rathee, S., Sharma, P., \&

450 Kohli, R. K. (2020). Patterns of plant communities along vertical gradient in

451 Dhauladhar Mountains in Lesser Himalayas in North-Western India. Science of The

452 Total Environment, 716, 136919. https://doi.org/10.1016/j.scitotenv.2020.136919

453 Ahmad, M. (2021). Species composition and floral trait diversity along an altitudinal gradient

454 in the western Himalaya. Graduate thesis, Panjab University, Chandigarh.

455 Barrett, S. C. H. (2010). Understanding plant reproductive diversity. Philosophical

456 Transactions of the Royal Society B: Biological Sciences, 365, 99-109.

457 https://doi:10.1098/rstb.2009.0199

458 Bellhouse, D.R. (2005). Systematic sampling methods. Encyclopedia of Biostatistics. John

459 Wiley \& Sons, New York. https://doi.org/10.1002/0470011815.b2a16077

460 Bello, F. D., Lavorel, S., Lavergne, S., Albert, C. H., Boulangeat, I., Mazel, F., \& Thuiller, W.

461 (2013). Hierarchical effects of environmental filters on the functional structure of plant

462 communities: a case study in the French Alps. Ecography, 36(3), 393-402.

463 https://doi.org/10.1111/j.1600-0587.2012.07438.x 
464 Bucher, S. F., \& Römermann, C. (2020). Flowering patterns change along elevational

465 gradients and relate to life-history strategies in 29 herbaceous species. Alpine Botany,

466 130(1), 41-58. https://doi.org/10.1007/s00035-020-00231-w

467 Burkle, L. A., \& Irwin, R. E. (2010). Beyond biomass: measuring the effects of

468 community $\square$ level nitrogen enrichment on floral traits, pollinator visitation and plant

469 reproduction. Journal of Ecology, 98(3), 705-717. https://doi.org/10.1111/j.1365-

$470 \quad 2745.2010 .01648 . x$

471 Campbell, D. R., \& Halama, K. J. (1993). Resource and pollen limitations to lifetime seed

472 production in a natural plant population. Ecology, 74(4), 1043-1051.

$473 \quad$ https://doi.org/10.2307/1940474

474 Conner, J. K., \& Rush, S. (1996). Effects of flower size and number on pollinator visitation to

475 wild radish, Raphanus raphanistrum. Oecologia, 105(4), 509-516.

476 https://doi:10.1007/BF00330014

477 Cordero, R. A., Fetcher, N., \& Voltzow, J. (2007). Effects of wind on the allometry of two

$478 \quad$ species of plants in an elfin cloud forest. Biotropica, 39(2), 177-185.

479 https://doi.org/10.1111/j.1744-7429.2006.00244.x

480 Crimmins, T. M., Crimmins, M. A., \& Bertelsen, C. D. (2013). Spring and summer patterns in

481 flowering onset, duration, and constancy across a water $\square$ limited gradient. American

482 Journal of Botany, 100(6), 1137-1147. https://doi.org/10.3732/ajb.1200633

483 de Bello, F., Carmona, C. P., Dias, A. T., Götzenberger, L., Moretti, M., \& Berg, M. P.

484 (2021). Handbook of trait-based ecology: from theory to R tools. Cambridge University

$485 \quad$ Press.

486 Dietrich, L., \& Körner, C. (2014). Thermal imaging reveals massive heat accumulation in

487 flowers across a broad spectrum of alpine taxa. Alpine Botany, 124(1), 27-35.

$488 \quad$ https://doi.org/10.1007/s00035-014-0123-1 
Dyer, A. G., Whitney, H. M., Arnold, S. E., Glover, B. J., \& Chittka, L. (2006). Bees associate warmth with floral colour. Nature, 442(7102), 525-525. https://doi.org/10.1038/442525a

E-Vojtkó, A., de Bello, F., Durka, W., Kuehn, I., \& Goetzenberger, L. (2020). The neglected importance of floral traits in trait-based plant community assembly. Journal of Vegetation Science, 31(4), 529-539. https://doi.org/10.1111/jvs.12877

Fabbro, T., \& Körner, C. (2004). Altitudinal differences in flower traits and reproductive allocation. Flora-Morphology, Distribution, Functional Ecology of Plants, 199(1), 7081. https://doi.org/10.1078/0367-2530-00128

Götzenberger, L., de Bello, F., Bråthen, K. A., Davison, J., Dubuis, A., Guisan, A., Lep̌̌, J., Lindborg, R., Moora, M., Pärtel, M., Pellissier, L., Pottier, J., Vittoz, P., Zobel, K., \& Zobel, M. (2012). Ecological assembly rules in plant communities—approaches, patterns and prospects. Biological reviews, 87(1), 111-127. https://doi.org/10.1111/j.1469-185X.2011.00187.x

Grime, J. P., Thompson, K., Hunt, R., Hodgson, J. G., Cornelissen, J. H. C., Rorison, I. H., Hendry, G. A. F., Ashenden, T. W., Askew, A. P., Band, S. R., Booth, R. E., Bossard,

511 Herrera, J. (2009). Visibility vs. biomass in flowers: exploring corolla allocation in 512 Mediterranean entomophilous plants. Annals of Botany, 103(7), 1119-1127. 513 https://doi.org/10.1093/aob/mcp046 
514 Jaswal A.K., Bhan S.C., Karandikar A.S, Gujar, M.K (2015). Seasonal and annual rainfall

515 trends in Himachal Pradesh during 1951-2005. Mausam, 66(2), 247-264.

516 Jaswal, A. K., Kumar, N., \& Khare, P. (2014). Climate variability in Dharamsala-a hill station

517 in western Himalayas. Journal of Indian Geophysical Union, 18(3), 336-355.

518 Jiménez $\square$ Alfaro, B., Silveira, F. A., Fidelis, A., Poschlod, P., \& Commander, L. E. (2016).

519 Seed germination traits can contribute better to plant community ecology. Journal of

$520 \quad$ Vegetation Science, 27(3), 637-645. https://doi.org/10.1111/jvs.12375

521 Kattel, D. B., Yao, T., Yang, K., Tian, L., Yang, G., \& Joswiak, D. (2013). Temperature lapse

522 rate in complex mountain terrain on the southern slope of the central Himalayas.

$523 \quad$ Theoretical and applied climatology, 113(3), 671-682. https://doi.org/10.1007/s00704-

$524 \quad 012-0816-6$

525 Keddy, P. A. (1992). Assembly and response rules: two goals for predictive community

526 ecology. Journal of vegetation science, 3(2), 157-164. https://doi.org/10.2307/3235676

527 Kiełtyk, P. (2021). Intraspecific morphological variation of Bellidiastrum michelii

528 (Asteraceae) along a 1,155 m elevation gradient in the Tatra Mountains. PeerJ, 9,

$529 \quad$ e11286. https://doi.org/10.7717/peerj.11286

530 Klatt, S., Schinkel, C. C., Kirchheimer, B., Dullinger, S., \& Hörandl, E. (2018). Effects of

531 cold treatments on fitness and mode of reproduction in the diploid and polyploid alpine

532 plant Ranunculus kuepferi (Ranunculaceae). Annals of botany, 121(7), 1287-1298.

533 https://doi: 10.1093/aob/mcy017

534 Klotz, S., Kühn, I., \& Durka, W. (2002). BIOFLOR-Eine Datenbank mit biologisch-

535 ökologischen Merkmalen zur Flora von Deutschland. - Bundesamt für Naturschutz,

536 Bonn - Bad Godesberg. https://wiki.ufz.de/biolflor/index.jsp

537 Körner, C. (2021). Alpine plant life: functional plant ecology of high mountain ecosystems

$538 \quad\left(3^{\text {rd }}\right.$ edistion). Springer Nature. https://doi:10.1007/978-3-642-18970-8 
539 Koski, M. H., \& Ashman, T. L. (2015). An altitudinal cline in UV floral pattern corresponds

540 with a behavioral change of a generalist pollinator assemblage. Ecology, 96(12), 3343-

541 3353. https://doi.org/10.1890/15-0242.1

542 Kraft, N. J., Valencia, R., \& Ackerly, D. D. (2008). Functional traits and niche-based tree

543 community assembly in an Amazonian Forest. Science, 322(5901), 580-582.

$544 \quad$ https://doi:10.1126/science. 1160662

545 Laiolo, P., \& Obeso, J. R. (2017). Life-history responses to the altitudinal gradient. In J.

546 Catalan, Josep. M, Ninot \& M. Mercè Aniz (eds.), High Mountain conservation in a

547 changing world (pp. 253-283). Springer Nature. https://doi.org/10.1007/978-3-319-

$548 \quad 55982-7 \_11$

549 Lambrecht, S. C., \& Dawson, T. E. (2007). Correlated variation of floral and leaf traits along

$550 \quad$ a moisture availability gradient. Oecologia, 151(4), 574-583.

$551 \quad$ https://doi.org/10.1007/s00442-006-0617-7

552 Laughlin, D. C. (2014). The intrinsic dimensionality of plant traits and its relevance to

553 community assembly. Journal of Ecology, 102(1), 186-193.

554 https://doi.org/10.1111/1365-2745.12187

Makino, T. T., \& Sakai, S. (2007). Experience changes pollinator responses to floral display size: from size $\square$ based to reward $\square$ based foraging. Functional Ecology, 21(5), 854-863. https://doi.org/10.1111/j.1365-2435.2007.01293.x

McGill, B. J., Enquist, B. J., Weiher, E., \& Westoby, M. (2006). Rebuilding community ecology from functional traits. Trends in ecology \& evolution, 21(4), 178-185. https://doi.org/10.1016/j.tree.2006.02.002 
565 Norgate, M., Boyd-Gerny, S., Simonov, V., Rosa, M. G., Heard, T. A., \& Dyer, A. G. (2010).

566 Ambient temperature influences Australian native stingless bee (Trigona carbonaria)

$567 \quad$ preference for warm nectar. PLoS One, 5(8), e12000.

568 https://doi.org/10.1371/journal.pone.0012000

Obeso, J. R. (2002). The costs of reproduction in plants. New phytologist, 155(3), 321-348. https://doi.org/10.1046/j.1469-8137.2002.00477.x

Oksanen, J., Blanchet, F. G., Friendly, M., Kindt, R., Legendre, P., McGlinn, D., Minchin, P. R., O'Hara, R. B., Simpson, G. L., Solymos, P., Stevens, M. H. H., Szoecs, E., \& Wagner, H. (2019). vegan: Community Ecology Package. R package version 2.5-6. https://CRAN.R-project.org/package=vegan Cornelissen, J. H. C. (2016). Corrigendum to: new handbook for standardised measurement of plant functional traits worldwide. Australian Journal of botany, 64(8),

Pillar, V. D., Sabatini, F. M., Jandt, U., Camiz, S., \& Bruelheide, H. (2021). Revealing the functional traits linked to hidden environmental factors in community assembly. Journal of Vegetation Science, 32(1), e12976. https://doi.org/10.1111/jvs.12976 
589 Ram, J., Singh, S. P., \& Singh, J. S. (1988). Community level phenology of grassland above 590 treeline in central Himalaya, India. Arctic and Alpine Research, 20(3), 325-332. https://doi:10.1080/00040851.1988.12002680

592

Rao, C. R. (1982). Diversity and dissimilarity coefficients: a unified approach. Theoretical population biology, 21(1), 24-43. https://doi.org/10.1016/0040-5809(82)90004-1

Rawat, D. S. (2012). Flowering phenology on altitudinal gradient in the Himalaya. Current Science, 103(11), 1281-1284.

Ricotta, C., \& Moretti, M. (2011). CWM and Rao's quadratic diversity: a unified framework for functional ecology. Oecologia, 167(1), 181-188. https://doi.org/10.1007/s00442011-1965-5

Rosbakh, S., \& Poschlod, P. (2021). Plant community persistence strategy is

600

601

602

603

604 elevation $\square$ specific. Journal of Vegetation Science, 32(3), e13028.

605

Rosbakh, S., Pacini, E., Nepi, M., \& Poschlod, P. (2018). An unexplored side of regeneration 606 https://doi.org/10.1111/jvs.13028

Rosbakh, S., Hartig, F., Sandanov, D. V., Bukharova, E. V., Miller, T. K., \& Primack, R. B. (2021). Siberian plants shift their phenology in response to climate change. Global Change Biology, 27(18), 4435-4448. https://doi.org/10.1111/gcb.15744

Saatkamp, A., Cochrane, A., Commander, L., Guja, L. K., Jimenez $\square$ Alfaro, B., Larson, J., ... 610 \& Walck, J. L. (2019). A research agenda for seed $\square$ trait functional ecology. New Phytologist, 221(4), 1764-1775. https://doi.org/10.1111/nph.15502

612 Sabin, T. P., Krishnan, R., Vellore, R., Priya, P., Borgaonkar, H. P., Singh, B. B., \& Sagar, A. 613 (2020). In R. Krishnan, J. Sanjay, C. Gnanaseelan, M. Mujumdar \& A. Kulkarni (eds.), 
614 Climate change over the Himalayas. Assessment of climate change over the Indian

615 region (pp. 207-222). Springer, Singapore.

616 Samson, D. A., \& Werk, K. S. (1986). Size-dependent effects in the analysis of reproductive

617 effort in plants. The American Naturalist, 127(5), 667-680.

618 https://doi.org/10.1086/284512

619 Sargent, R. D., \& Ackerly, D. D. (2008). Plant-pollinator interactions and the assembly of 620 plant communities. Trends in Ecology \& Evolution, 23(3), 123-130.

$621 \quad$ https://doi.org/10.1016/j.tree.2007.11.003

622 Scherrer, D., \& Körner, C. (2011). Topographically controlled thermal $\square$ habitat differentiation

623 buffers alpine plant diversity against climate warming. Journal of Biogeography, 38(2),

624 406-416. https://doi.org/10.1111/j.1365-2699.2010.02407.x

625 Singh, J. S., \& Singh, S. P. (1987). Forest vegetation of the Himalaya. The Botanical Review, 626 53(1), 80-192. https://doi.org/10.1007/BF02858183

627 Soltis, P., \& Soltis, D. (2014). Flower diversity and angiosperm diversification. In J. L.

628 Riechmann \& F. Wellmer (Eds.), Flower development (pp. 85-102). Humana Press.

629 Spasojevic, M. J., \& Suding, K. N. (2012). Inferring community assembly mechanisms from

630 functional diversity patterns: the importance of multiple assembly processes. Journal of

$631 \quad$ Ecology, 100(3), 652-661. https://doi.org/10.1111/j.1365-2745.2011.01945.x

632 Tachiki, Y., Iwasa, Y., \& Satake, A. (2010). Pollinator coupling can induce synchronized

633 flowering in different plant species. Journal of Theoretical Biology, 267(2), 153-163.

634 https://doi.org/10.1016/j.jtbi.2010.08.023

635 Trunschke, J., \& Stöcklin, J. (2017). Plasticity of flower longevity in alpine plants is increased

636 in populations from high elevation compared to low elevation populations. Alpine

637 Botany, 127(1), 41-51. https://doi.org/10.1007/s00035-016-0176-4

638 Ulrich, J., Bucher, S. F., Eisenhauer, N., Schmidt, A., Türke, M., Gebler, A., Barry, K.,

639 Lange, M. and Römermann, C. (2020). Invertebrate decline leads to shifts in plant 
species abundance and phenology. Frontiers in plant science, 11, p1410.

641 https://doi.org/10.3389/fpls.2020.542125

642 Valencia, E., Méndez, M., Saavedra, N., \& Maestre, F. T. (2016). Plant size and leaf area influence phenological and reproductive responses to warming in semiarid Mediterranean species. Perspectives in Plant Ecology, Evolution and Systematics, 21, 31-40. https://doi.org/10.1016/j.ppees.2016.05.003

van der Kooi, C. J., Kevan, P. G., \& Koski, M. H. (2019). The thermal ecology of flowers.

647 Annals of Botany, 124(3), 343-353. https://doi.org/10.1093/aob/mcz073

648 Violle, C., Navas, M. L., Vile, D., Kazakou, E., Fortunel, C., Hummel, I., \& Garnier, E. 649 (2007). Let the concept of trait be functional! Oikos, 116(5), 882-892. https://doi.org/10.1111/j.0030-1299.2007.15559.x

Wagner, J., Ladinig, U., Steinacher, G., \& Larl, I. (2011). From the flower bud to the mature seed: timing and dynamics of flower and seed development in high-mountain plants. In C. Lütz (eds.), Plants in alpine regions (pp. 135-152). Springer Science \& Business Media. DOI:10.1007/978-3-7091-0136-0_10

Weiher, E., Freund, D., Bunton, T., Stefanski, A., Lee, T., \& Bentivenga, S. (2011). Advances, challenges and a developing synthesis of ecological community assembly theory. Philosophical Transactions of the Royal Society B: Biological Sciences, 366(1576), 2403-2413. https://doi.org/10.1098/rstb.2011.0056

Woodward, F. I., \& Woodward, F. I. (1987). Climate and plant distribution. Cambridge University Press.

661 Zhang, S., Liu, G., Cui, Q., Huang, Z., Ye, X., \& Cornelissen, J. H. (2021). New field wind 662 manipulation methodology reveals adaptive responses of steppe plants to increased and 663 reduced wind speed. Plant Methods, 17(1), 1-16. https://doi.org/10.1186/s13007-020$00705-2$ 
665 Zhao, Y. H., Ren, Z. X., Lázaro, A., Wang, H., Bernhardt, P., Li, H. D., \& Li, D. Z. (2016).

666 Floral traits influence pollen vectors' choices in higher elevation communities in the

667 Himalaya-Hengduan Mountains. BMC Ecology, 16(1), 1-8.

668 https://doi.org/10.1186/s12898-016-0080-1

669 Zhu, Y., Siegwolf, R. T., Durka, W., \& Körner, C. (2010). Phylogenetically balanced

670 evidence for structural and carbon isotope responses in plants along elevational

671 gradients. Oecologia, 162(4), 853-863. https://doi.org/10.1007/s00442-009-1515-6 